$$
\begin{gathered}
\text { 아동기 외상 경험과 문제행동에 대한 청소년 자신과 } \\
\text { 부모 평가 간의 관계 : 비행청소년과 일반청소년 비교 } \\
\text { 유재학 }{ }^{1)} \text { 서민재 }{ }^{1)} \text { - 박지선 }{ }^{2)} \\
\text { 건국대학교 의학전문대학원 정신건강의학교실, }{ }^{1)} \text { 부산가톨릭대학교 사회복지상담학과2) }
\end{gathered}
$$

\title{
The Relationship between Childhood Trauma Experience and Parent-Adolescent Reports of Problem Behavior : Comparison of Delinquent and General Adolescent
}

\author{
Jaehak Yu, M.D. ${ }^{1)}$, Min-Jae Seo, M.A. ${ }^{1)}$ and Jisun Park, Ph.D. ${ }^{2)}$ \\ ${ }^{1)}$ Department of Psychiatry, Konkuk University Medical Center, Seoul, Korea \\ ${ }^{2)}$ Department of Social Welfare \& Counseling, Catholic University of Pusan, Busan, Korea
}

Objectives : The aim of this study was to investigate correlation of childhood trauma experience and parent-adolescents' assessment reports on problem behavior through comparison of delinquent and general adolescents.

Methods : First, delinquent adolescents and general adolescents were asked to complete the Childhood Trauma Questionnaire (CTQ). Then, 71 pairs of delinq uent adolescents and their parents and 133 pairs of general adolescents and their parents were asked to complete the Korean Youth Self-Report (K-YSR) and the Korean Child Behavior Checklist (K-CBCL). Finally, responses from 410 people were used for the analysis.

Results : First, childhood trauma experience score was significantly higher for delinquent adolescents, compared to general adolescents. Second, t-test showed a greater difference between K-YRS and K-CBCL for general adolescents than for delinquent adolescents. Third, in the case of delinquent adolescents, the correlation analysis of K-YSR filled out by adolescents and K-CBCL filled out by parents showed significant correlation in certain areas, including social immaturity, delinquent behaviors, internalization issues, and externalization issues. On the other hand, the correlation analysis of K-YSR and K-CBCL of general adolescents showed significant correlation in all sub-categories. Fourth, the correlation analysis of delinquent adolescents' CTQ and K-YSR showed minimal yet significant correlation in social adaptation, withdrawing, depression/anxiety, and delinquent/aggressive behaviors, however, no correlation was observed between CTQ and K-CBCL. The correlation analysis of general adolescents' CTQ and K-YSR, and CTQ and K-CBCL showed significant correlation in all sub-categories, although the degree of correlation varied.

Conclusion : Delinquent adolescents had more childhood traumatic experiences. However, general adolescents' childhood traumatic experiences showed minimal yet significant correlation with various adaptation indicators and their parents responded in a similar way, indicating that general adolescents with childhood traumatic experiences need close care and attention even if they have not shown prominent delinquent behaviors.

KEY WORDS : Adolescent · Childhood Trauma Experience · Korean Child Behavior Checklist · Korean Youth Self-Report.

$\begin{array}{cl}\text { 서 론 } & \text { 는지에 따라 스트레스가 개인에게 미치는 영향력은 각기 다 } \\ & \text { 를 수 있다. 먼저 스트레스를 경험한 시기의 측면에서 볼 때, } \\ \text { 인간은 살아가면서 많은 스트레스를 경험한다. 그러나 스 } & \text { 아동이 경험한 고통스러운 스트레스는 아동에게 깊은 상처를 }\end{array}$

접수완료 :2012년 11월 30일 / 수정완료:2013년 1월 28일 / 심사완료 :2013년 2월 7일

Address for correspondence: Jisun Park, Ph.D., Department of Social Welfare \& Counseling, Catholic University of Pusan, 57 Oryundae-ro, Geumjeong-gu, Busan 609757 , Korea

Tel : +82.51-510-0676, Fax : +82.51-510-0679, E-mail : lala@cup.ac.kr.

이 논문은 2010년도 건국대학교병원 임상연구비 지원을 받았음. 
준다.) 성인은 인지발달이 충분히 이루어져 자신이 경험한 사 건을 이해하고 처리하는 신념체계가 발달해 있지만, 아동은 그렇지 못하기 때문에 ${ }^{2}$ 아동기의 심각한 스트레스 경험은 나 이가 어릴수록 더 분명한 영향을 미치게 되는 것이다. ${ }^{3)}$

다음으로 스트레스 종류의 측면에서 볼 때, 가장 심각한 스 트레스 반응을 불러일으킬 수 있는 것이 외상경험이다. 외상 은 크게 사건외상(event trauma)과 진행외상(process trauma) 으로 나눌 수 있다. ${ }^{4)}$ 먼저 사건외상은 제한된 시간이나 공간 에서 뜻하지 않은 갑작스런 스트레스 사건으로 인해 생긴 외 상을 말하는 반면, 진행외상은 학대나 방임과 같은 스트레스 사건에 지속적으로 노출되어 생긴 외상을 말한다. 진행외상 은 이후 발달, 정서, 및 행동문제를 발생시킬 뿐 아니라 성격 형성에도 영향을 미친다. 외상을 일으킨 대상이 사람이고 고 의성이 개입된 경우, 자연이나 우연에 의해 생긴 외상보다 더 견디기가 힘들다. 무엇보다도 진행외상에 속하는 학대나 방 임은 주로 아동과 가까운 타인에 의해 경험됨에 주목할 필요 가 있다. 부모나 유의미한 타인과의 관계에서 경험한 다양한 학대경험은 인위적이고 반복적인 외상에 속하는 것으로, 가장 심각한 영향을 미치는 외상의 대표적인 예가 된다. ${ }^{5)}$ 이렇게 지속적으로 학대를 경험한 아동은 간헐적으로 혹은 일회성 학대를 받은 아동에 비해 후유증이 훨씬 더 심각했다.)

많은 연구들이 아동기의 외상경험과 청소년기나 성인기의 적응과의 관계를 보고해 왔다. 아동기 외상경험은 훗날의 정 신병리 즉, 우울, 불안,7) 알코올문제, ${ }^{8}$ 빈약한 사회기술, ${ }^{9}$ 성격 장애, ${ }^{10)}$ 주의력결핍 과잉행동장애, 외상 후 스트레스 장애, ${ }^{11}$ 자기혐오, 해리, 자기 파괴적인 행동, 대인관계 문제 및 건강염 려증 ${ }^{12)}$ 등과 관련이 있었다. 또한 아동의 학대경험은 비행이나 범죄 등과 관련이 있었는데, ${ }^{13)}$ Hoffman-Plotkin과 Twenty$\operatorname{man}^{14)}$ 은 학대 후유중이 큰 아이들이 약물에 탐닉하는 퇴행 현상을 보이거나 충동적 성격, 인내심 결핍 등으로 도둑질을 하거나 공격적인 행동을 하는 등 일탈행동에 빠지기가 더 쉽 다고 보고하였다. Cerezo은 즌 집 관찰을 통해 학대받은 아 동이 그렇지 않은 아동에 비해 일탈행동 비율이 더 높았다고 보고하였다. 국내에서도 아동기 때 빈번한 신체 및 언어폭력 을 경험한 경우, 청소년기에 비행을 더 많이 보였으며, 비행을 행하는 시기도 더 빠른 것으로 보고되었다. ${ }^{16)}$ 또한 부모로부 터 학대를 경험한 비행청소년은 일반청소년에 비해 자기통제 력이 더 많이 떨어졌다. ${ }^{17)}$ 이와 같이 아동기 학대경험은 청소년 의 비행이나 범죄와도 관련이 있으므로 본 연구에서도 비행 으로 소년원에 입원 중인 청소년과 일반청소년을 대상으로 그들의 학대경험을 비교하려 한다.

Achenbach ${ }^{18}$ 는 아동은 물론 청소년들의 정서 및 행동문제 를 평가할 때 한 가지 보고나 관찰만으로 평가하는 것은 위험
하다고 지적하면서 이들과 관계가 있는 사람들이 평가한 자료 를 모아 함께 통합해야 한다고 제안하였다. 이에 따라 국내에 서 표준화작업이 진행된 한국판 아동 청소년 행동평가척도 (Korean Child Behavior Checklist, K-CBCL)와 이와 동일 한 체계를 갖는 한국판 청소년 자기 행동평가척도(Korean Youth Self-Report, K-YSR)를 동일한 청소년에게 함께 실시 하여 두 평가자의 평가가 서로 관련이 있는지의 여부를 살펴보 는 것이 청소년의 정서 및 행동문제를 이해하는 데 도움이 될 것 이다.

아동 및 청소년 정신병리 분야에서 가장 영향력 있는 두 가 지 정신의학적 분류체계는 서로 다른 토대를 지닌 접근 체계 에서 나온 것으로, 그 중 하나는 임상적-진단적 접근을 대표하 는 정신장애의 진단 및 통계 편람 체계이며, 다른 하나는 경 험적·양적 접근을 대표하는 아동행동 체크리스트 점수 체계 이다. ${ }^{19)} \mathrm{CBCL}$ 은 아동과 청소년의 행동 및 정서 문제에 대한 체크리스트 형태의 부모 평가도구로서, 모집단의 실제 점수 분포에 기초하여 증상에 대한 표준화된 기준을 제공한다. ${ }^{20)}$ $\mathrm{CBCL}^{18)}$ 은 4-18세 아동의 부모들이 작성할 수 있고, $\mathrm{YSR}^{21)}$ 은 11-18세 청소년들이 스스로 응답하는 평가도구로 내재화 나 외현화같은 넓은 범위의 증후군뿐 아니라 좁은 범위의 8 개의 증후군들(위축, 신체증상, 우울/불안, 사회적 미성숙, 사 고의 문제, 주의집중 문제, 비행, 공격성)을 평가할 수 있다.

$\mathrm{K}-\mathrm{CBCL}$ 은 부모가 평정하는 행동평가척도로 전반적인 아동-청소년기의 문제행동을 측정하기 위해 상담소, 학교, 종합병원 등 여러 임상장면에서 널리 사용되고 있는 척도이다. $\mathrm{K}-\mathrm{CBCL}$ 은 $\mathrm{K}-\mathrm{YSR}$ 과 유사한 영역의 아동 및 청소년기 문제 행동을 측정하기에 $\mathrm{K}-\mathrm{CBCL}$ 을 통해 부모가 평정한 평가내 용과 아동·청소년이 $\mathrm{K}-\mathrm{YSR}$ 을 통해 평정한 평가 내용 간의 일 치도를 다각적으로 살펴보고 비교할 수 있다. ${ }^{22)}$ 이러한 특성 으로 인하여 지금까지 아동, 청소년의 자기행동평가와 부모의 평가결과의 일치 정도 및 여기에 영향을 미치는 요인에 대한 다양한 연구가 수행되었다. ${ }^{23)}$

그동안 문제행동에 대한 청소년 자신과 부모 평가 간의 관계 에 대해서는 연구가 이루어져 왔지만 비행청소년을 대상으로 한 연구는 이루어지지 못했다. 특히 비행으로 인해 소년원에 입 원한 경우, 비행청소년 개인에 대한 부모의 평정치 $(\mathrm{K}-\mathrm{CBCL})$ 를 얻기가 힘들었기 때문이었던 것으로 추측된다. 이러한 점 에 착안하여 본 연구에서는 아동기 외상경험과 청소년기 문제 행동과의 관계를 살펴볼 때, 일반청소년과 비행청소년을 대 상으로 비교할 것이며 다양한 문제행동에 있어 양육자와 청소 년 스스로가 평가한 결과 간의 관계도 살펴보려 한다. 


\section{방 법}

\section{1. 대 상}

비행청소년들의 아동기외상경험과 적응을 알아보기 위해 경기도에 위치한 소년원에 입원 중인 남자 청소년 82명에게 아동기외상질문지와 한국판 청소년 자기행동평가척도 $\left(\mathrm{K}^{-}\right.$ YSR)를 실시하였다. 그 중에서 73명의 보호자가 소년원으로 면담을 왔을 때 그 보호자를 대상으로 한국판 아동청소년 행동평가척도 $(\mathrm{K}-\mathrm{CBCL})$ 를 실시하였다. 비행청소년의 자료에 서는 $\mathrm{K}-\mathrm{CBCL}$ 을 동생이 대신 평가한 자료 1 부를 제외한 후 총 72 쌍의 자료를 분석에 사용하였다. 일반청소년의 경우 서울소 재 일반 남자고등학교에 재학 중인 학생들을 대상으로 연구 안내문을 배포하여 연구 참여 희망자를 모집하였다. 총 133 명 의 청소년이 부모와 상의한 후 연구에 참여하기를 희망하여 서류 봉투에 비행청소년에게 실시한 것과 동일한 설문지를 넣어 각 학생에게 배부한 후 집에 가져가 청소년과 그의 부 모가 각자 자신의 설문지를 작성한 후에 제출하도록 하였다. 인구통계학적 정보 중 가정의 경제상황에 관한 정보는 연구 에 참여한 학생의 자가 보고로, 부모님의 교육 정도는 부모님 의 보고에 의해 획득되었다. 주관적인 연구에 참여한 비행청 소년과 일반청소년 본인과 그의 부모에게 연구 내용과 그 과 정을 서면으로 상세히 설명한 후 연구 참여에 관한 동의를 얻었다.

\section{2. 측정도구}

\section{1) 아동기외상질문지(Childhood Trauma Questionnaire, CTQ)}

Bernstein과 Fink ${ }^{24}$ 의 아동기외상질문지를 정신건강의학 과 전문의가 한국말로 번안한 다음 임상심리학자가 검토한 후 정신건강의학과 전문의, 전공의, 임상심리전문가가 토의작업 을 거쳐 최종적으로 완성된 것을 사용하였다. 이 질문지는 정 서학대, 신체학대, 성학대, 정서방임, 신체방임의 다섯 가지 하 위척도와 타당도척도 3 문항으로 구성되어 있다. 모든 하위척 도는 5점 리커트 척도로 측정한다. 본 연구는 외상 유형을 알 아보는데 그 목적이 있는 것이 아니기에 다섯 가지의 하위척도 의 모든 점수를 더하여 아동기외상점수로 사용하였다.

\section{2) 한국판 청소년 자기 행동평가척도(Korean Youth Self-Report, K-YSR)}

Achenbach가 개발한 것을 $\mathrm{Oh}$ 등 ${ }^{25)}$ 이 표준화한 척도를 사 용하였다. 이 척도는 12-17세 청소년이 자신의 적응과 정서, 행
동에 대해 평가하는 것으로 크게 사회능력척도와 문제행동 증후군척도로 구성되어 있다. 모든 하위척도는 규준에 제시된 $\mathrm{T}$ 점수를 사용하였다.

\section{3) 한국판 아동 청소년 행동평가척도(Korean Child Behavior Checklist, $\mathrm{K}-\mathrm{CBCL}$ )}

Achenbach가 개발한 것을 국내에서는 $\mathrm{Oh}$ 등 $^{26}$ 이 표준화 하였다. 이 척도는 부모가 4-17세 자녀를 대상으로 다양한 적 응 및 부적응 행동, 정서적 문제에 대해 평가한다. 모든 하위척 도는 규준에 제시된 $\mathrm{T}$ 점수를 사용하였다.

\section{4) 자료분석}

통계분석에는 비행청소년 72쌍의 자료(비행청소년과 그의 보호자), 일반청소년 133쌍의 자료(일반청소년과 그의 보호자), 총 410 명의 자료가 사용되었다. 먼저 본 연구의 참여자에 관 한 인구통계학적 정보를 살펴보았고 비행청소년과 일반청소 년의 아동기외상경험 차이를 알아보기 위해 $\mathrm{t}$-test를 실시하 였다. 두번째로 청소년의 K-YSR과 보호자의 $\mathrm{K}-\mathrm{CBCL}$ 자료 의 상관을 살펴보았다. 세번째로 청소년이 보고한 아동기외상 경험 점수와 $\mathrm{K}-\mathrm{YSR}$, 그리고 $\mathrm{K}-\mathrm{CBCL}$ 점수 간 상관 정도를 알아보았다. 통계프로그램은 SPSS 15.0 version을 사용하였다.

\section{결 과}

\section{1. 인구통계학적 자료(Table 1)}

대상자는 모두 남학생이었으며, 비행청소년의 연령은 15세 에서 20세로 평균연령은 16.53 [standard deviation(SD)=1.42] 이었고, 일반청소년의 연령은 15 세에서 19세로 평균연령은 $16.77(\mathrm{SD}=0.52)$ 이었다. 아동기외상척도(Childhood Trauma Questionnaire, CTQ) 점수는 비행청소년과 일반청소년 간 유 의한 차이를 보였는데 비행청소년이 일반청소년에 비해 아동 기 외상경험이 더 많았다 $(\mathrm{t}=2.28, \mathrm{p}<.05)$. 청소년의 적응력에 관한 정보를 알아보기 위해 보호자를 대상으로 실시된 $\mathrm{K}-$ $\mathrm{CBCL}$ 의 경우 비행청소년은 아버지와 어머니에 의해 작성된 사례가 많았고(90.3\%) 나머지(9.7\%)는 조부모와 고모, 형 등의 가까운 친척이었다. 일반청소년의 경우 모두 아버지나 어머니 가 작성하였는데 어머니가 작성한 사례(80.5\%)가 아버지가 작 성한 사례(5.8\%)보다 훨씬 더 많았다.

\section{2. $\mathrm{K}-\mathrm{YSR}$ 과 $\mathrm{K}-\mathrm{CBCL}$ 간 집단 간 비교(Table 2)}

다양한 문제행동 영역에 관한 청소년과 보호자 보고에서 차 이가 있는지 알아보기 위해 t-test를 실시하였다. 그 결과, 본 연구에 참여한 모든 청소년을 대상으로 했을 때 내재화 문제 
를 제외한 모든 적응영역에서 청소년 보고와 부모 보고 간 차이가 유의한 것으로 나타났다. 좀 더 자세히 살펴보면 우선 사회능력척도 중 사회성과 학업수행 영역에서는 청소년 자신 보다 보호자가 청소년의 능력을 더 높게 평가하였다 $(\mathrm{p}<.001)$. 행동문제척도에서는 위축, 우울/불안, 신체화, 사회적 미성 숙, 사고의 문제, 주의력 문제, 공격행동(모두 $\mathrm{p}<.001$ ), 비행
과 외현화 문제 $(\mathrm{p}<.05)$ 영역에서 보호자보다 청소년이 더 높게 평가하였다.

비행청소년 집단과 일반청소년 집단을 따로 분석한 결과, 비행청소년 집단에서는 학업 영역에서 청소년 자신이 보호자보 다 자신의 학업 능력을 더 양호한 것으로 평가하였다 $(\mathrm{p}<.001)$. 행동문제 영역에서는 신체화와 사회적 미성숙척도 $(\mathrm{p}<.05)$ 에

Table 1. Demographic variables among adolescent groups

\begin{tabular}{|c|c|c|c|}
\hline Variable & & $\begin{array}{c}\text { Delinquent adolescent }(\mathrm{N}=72) \\
\text { Mean } \pm S D\end{array}$ & $\begin{array}{c}\text { General adolescent }(\mathrm{N}=133) \\
\text { Mean } \pm \mathrm{SD}\end{array}$ \\
\hline Age (years) & & $16.53 \pm 1.42$ & $16.77 \pm 0.52$ \\
\hline CTQ & & $40.40 \pm 12.07$ & $36.82 \pm 9.95$ \\
\hline \multicolumn{4}{|l|}{ Economic state, N (\%) } \\
\hline High & & $1(1.4)$ & $10(7.5)$ \\
\hline Medium & & $62(86.1)$ & $120(90.2)$ \\
\hline Low & & $9(12.5)$ & $3(2.3)$ \\
\hline \multicolumn{4}{|c|}{ Parent's education year } \\
\hline \multirow[t]{5}{*}{ Father } & $\leq 6$ years & $3(4.2)$ & $0(0)$ \\
\hline & 9 years & $14(19.4)$ & $1(0.8)$ \\
\hline & 12 years & $37(51.4)$ & $10(7.5)$ \\
\hline & $\geq 16$ years & $11(15.3)$ & $118(88.7)$ \\
\hline & Missing & $7(9.7)$ & $4(3.0)$ \\
\hline \multirow[t]{5}{*}{ Mother } & $\leq 6$ years & $1(1.4)$ & $1(0.8)$ \\
\hline & 9 years & $11(15.3)$ & $1(0.8)$ \\
\hline & 12 years & $39(54.2)$ & $20(15.0)$ \\
\hline & $\geq 16$ years & $11(15.3)$ & $107(80.5)$ \\
\hline & Missing & $10(13.9)$ & $4(3.0)$ \\
\hline \multicolumn{4}{|c|}{ Person who responds the $\mathrm{K}-\mathrm{CBCL}$} \\
\hline Father & & $34(47.2)$ & $21(15.8)$ \\
\hline Mother & & $31(43.1)$ & $112(84.3)$ \\
\hline And so on & & $7(9.7)$ & \\
\hline
\end{tabular}

CTQ : Childhood Trauma Questionnaire, SD : standard deviation, N : number, economic state : adolescents' subjective rate, K-CB$\mathrm{CL}$ : Korean Child Behavior Checklist

Table 2. Comparison between subscale score of K-YSR and K-CBCL

\begin{tabular}{|c|c|c|c|c|c|c|}
\hline \multirow{2}{*}{ Subscale } & \multicolumn{2}{|c|}{ All } & \multicolumn{2}{|c|}{ Delinquent adolescent } & \multicolumn{2}{|c|}{ General adolescent } \\
\hline & $\dagger$ & df & $t$ & df & $t$ & $\mathrm{df}$ \\
\hline \multicolumn{7}{|l|}{ Social competence } \\
\hline Social & $-4.723^{\dagger}$ & 204 & -.634 & 71 & $-5.766^{中}$ & 132 \\
\hline School & $-2.588^{*}$ & 204 & $5.686^{中}$ & 71 & $-13.118^{\phi}$ & 132 \\
\hline \multicolumn{7}{|l|}{ Behavior problem } \\
\hline Withdrawn & $5.559^{*}$ & 204 & -.639 & 71 & $8.376^{+}$ & 132 \\
\hline Somatic complaints & $8.459^{\dagger}$ & 204 & $3.274^{\dagger}$ & 71 & $8.609^{\phi}$ & 132 \\
\hline Anxious/Depressed & $6.902^{+}$ & 204 & .429 & 71 & $9.232^{+}$ & 132 \\
\hline Social problems & $6.006^{+}$ & 204 & $2.307^{*}$ & 71 & $6.151^{*}$ & 132 \\
\hline Thought problems & $3.934^{*}$ & 204 & -1.254 & 71 & $8.007^{\phi}$ & 132 \\
\hline Attention problems & $4.992^{\dagger}$ & 204 & $-2.636^{\dagger}$ & 71 & $10.134^{\dagger}$ & 132 \\
\hline Delinquent behavior & $2.090^{*}$ & 204 & $-5.290^{\phi}$ & 71 & $9.272^{\phi}$ & 132 \\
\hline Aggressive behavior & $9.278^{+}$ & 204 & 1.512 & 71 & $11.484^{\dagger}$ & 132 \\
\hline Internalizing problems & 1.804 & 204 & $-3.048^{\dagger}$ & 71 & $5.352^{\dagger}$ & 132 \\
\hline Externalizing problems & $2.651^{\dagger}$ & 204 & $-2.782^{\dagger}$ & 71 & $6.230^{\phi}$ & 132 \\
\hline
\end{tabular}

$*: p<.05, \dagger: p<.01, \dagger^{\ddagger}: p<.001$. t-test on groups differences between delinquent and general adolescents' K-YSR and K-CBCL, K-YSR : Korean Youth Self-Report, K-CBCL : Korean Child Behavior Checklist 
서 청소년의 점수가 보호자의 점수보다 더 높았으나 주의력 문 제, 내재화와 외현화 $(\mathrm{p}<.05)$, 그리고 비행 $(\mathrm{p}<.001)$, 영역에서 는 청소년의 점수보다 보호자의 점수가 더 높았다.

비행청소년 집단과는 달리 일반청소년 집단에서는 모든 적 응지표에서 청소년과 보호자의 점수 차이가 유의한 것으로 나 타났다. 좀 더 자세히 살펴보면 사회성과 학업 영역에서는 청 소년이 보호자보다 자신의 능력을 더 과소평가했으며, 위축, 신체화, 우울/불안, 사회적 미성숙, 사고의 문제, 주의력 문제, 비행, 공격성과 내재화 및 외현화 영역 모두에서 청소년 자신 이 평가한 점수가 보호자가 평가한 점수보다 유의하게 더 높 았다 $(\mathrm{p}<.001)$.

\section{3. 청소년 자신 $(\mathrm{K}-\mathrm{YSR})$ 과 보호자 $(\mathrm{K}-\mathrm{CBCL})$ 간의 관계(Table 3)}

청소년의 정서 및 행동문제에 대해 청소년 자신과 보호자가 평가한 것의 상관관계를 알아보았다. 비행청소년의 경우 내재 화문제, 외현화 문제, 사회적 미성숙, 비행행동에서 유의미한 정적 상관을 보였다.

비행청소년과는 달리 일반청소년은 청소년 자신이 보고한 적응 지표 점수와 보호자가 보고한 청소년의 모든 적응 지표 가 유의미한 정적 상관을 보였다.

\section{4. 청소년의 아동기외상경험과 청소년 자신이 평가한 정서 및 행동문제와의 관계(Table 4)}

아동기외상경험과 청소년의 적응 간 관계를 알아보기 위해 청소년의 $\mathrm{CTQ}$ 점수와 $\mathrm{K}-\mathrm{YSR}$ 하위척도 간 상관분석을 실시 하였다. 그 결과, 비행청소년의 경우, 아동기외상경험과 사회

Table 3. Correlation between subscale scores of K-YSR and K$\mathrm{CBCL}$

\begin{tabular}{lcc}
\hline \multicolumn{1}{c}{ Subscale } & $\begin{array}{c}\text { Delinquent } \\
\text { adolescent } \\
\text { group }(\mathrm{N}=144)\end{array}$ & $\begin{array}{c}\text { General } \\
\text { adolescent } \\
\text { group }(\mathrm{N}=266)\end{array}$ \\
\hline $\begin{array}{l}\text { Social competence } \\
\text { Social }\end{array}$ & -.048 & $.220^{*}$ \\
School & .094 & $.562^{\dagger}$ \\
Behavior problem & .061 & \\
Withdrawn & .154 & $.177^{*}$ \\
Somatic complaints & .101 & $.255^{\dagger}$ \\
Anxious/Depressed & $.329^{\dagger}$ & $.301^{\dagger}$ \\
Social problems & .082 & $.270^{\dagger}$ \\
Thought problems & .145 & $.227^{\dagger}$ \\
Attention problems & $.352^{\dagger}$ & $.275^{\dagger}$ \\
Delinquent behavior & .231 & $.277^{\dagger}$ \\
Aggressive behavior & $.253^{*}$ & $.348^{\dagger}$ \\
Internalizing problems & $.371^{\dagger}$ & $.237^{\dagger}$ \\
Externalizing problems & & \\
\hline * : p <.05, $\dagger$ : p<.01. K-YSR : Korean Youth Self-Report, K-CBCL: \\
Korean Child Behavior Checklist
\end{tabular}

능력척도는 통계적으로 유의한 부적 상관을 보였다. 그리고 위 축, 우울/불안, 비행, 공격성척도와는 통계적으로 유의한 정적 인 상관을 보였다. 그러나 일반 청소년의 경우, 사회능력척도를 제외한 모든 행동문제척도에서 통계적으로 유의한 정적 상관 을 보였다.

\section{5. 청소년의 아동기외상경험과 보호자가 평가한 청소년의 정서 및 행동문제와의 관계(Table 5) \\ 청소년의 아동기외상경험과 보호자가 평가한 청소년의 정}

Table 4. Correlation between scores of CTQ and K-YSR

\begin{tabular}{lcc}
\hline & $\begin{array}{c}\text { CTQ score of } \\
\text { delinquent } \\
\text { adolescent } \\
(\mathrm{N}=144)\end{array}$ & $\begin{array}{c}\text { CTQ score } \\
\text { general } \\
\text { adolescent } \\
(\mathrm{N}=266)\end{array}$ \\
\hline Social competence & $-.335^{\dagger}$ & -.168 \\
Social & -.099 & -.085 \\
School & $.254^{*}$ & $.233^{*}$ \\
Behavior problem & .148 & $.215^{*}$ \\
Withdrawn & $.252^{*}$ & $.283^{\dagger}$ \\
Somatic complaints & .177 & $.202^{*}$ \\
Anxious/Depressed & .097 & $.240^{\dagger}$ \\
Social problems & .193 & $.377^{\dagger}$ \\
Thought problems & $.236^{*}$ & $.281^{\dagger}$ \\
Attention problems & $.235^{*}$ & $.171^{*}$ \\
Delinquent behavior & .137 & $.415^{\dagger}$ \\
Aggressive behavior & .192 & $.274^{\dagger}$ \\
Internalizing problems & & \\
Externalizing problems & . &
\end{tabular}

Table 5. Correlation between scores of $\mathrm{CTQ}$ and $\mathrm{K}-\mathrm{CBCL}$

\begin{tabular}{lcc}
\hline & $\begin{array}{c}\text { Delinquent } \\
\text { adolescent } \\
(\mathrm{N}=144)\end{array}$ & $\begin{array}{c}\text { General } \\
\text { adolescent } \\
(\mathrm{N}=266)\end{array}$ \\
\hline Social competence & -.155 & $-.229^{\dagger}$ \\
Social & -.123 & .038 \\
School & .060 & $.207^{*}$ \\
Behavior problem & .175 & .138 \\
Withdrawn & .173 & $.175^{*}$ \\
Somatic complaints & -.017 & $.191^{*}$ \\
Anxious/Depressed & .153 & .139 \\
Social problems & .042 & $.204^{*}$ \\
Thought problems & .181 & $.206^{*}$ \\
Attention problems & .083 & $.313^{\dagger}$ \\
Delinquent behavior & .192 & $.260^{\dagger}$ \\
Aggressive behavior & .141 & $.294^{\dagger}$ \\
Internalizing problems & Externalizing problems & .
\end{tabular}


서 및 행동문제와의 관계를 알아보기 위해 상관분석을 실시 하였다. 그 결과, 비행청소년의 경우, 청소년의 아동기외상경험 과 정서 및 행동문제는 유의미한 상관이 없는 것으로 확인되 었다. 그러나 일반청소년의 경우, 청소년의 아동기외상경험과 사회능력은 부적으로 유의한 상관이 있었으나, 내재화, 외현화, 총문제행동, 위축, 우울/불안, 사회적 미성숙, 주의력 문제, 비 행, 공격성과는 유의한 정적 상관이 있는 것으로 나타났다.

\section{고 찰}

본 연구의 주된 목적은 청소년의 아동기외상경험과 현재의 정서 및 행동문제와의 관계를 알아보려는 것이었다. 이를 수 행함에 있어 그동안 문제행동에 대한 청소년 자신과 부모 평 가 간의 관계에 대해서는 연구가 이루어져 왔지만 비행청소년 을 대상으로 한 연구는 이루어지지 못했다는 점에 착안하여 청소년의 정서 및 행동문제는 청소년의 자가 보고와 부모 평 가 자료를 활용하였다.

먼저 비행청소년과 일반청소년의 아동기외상경험을 비교 해 본 결과, 비행청소년이 일반청소년에 비해 아동기외상경험 을 더 많이 보고하였다. 이와 같은 결과는 학대경험이 비행이 나 범죄 등과 같은 심리적 부적응과 관련이 있다는 기존 연구 결과 ${ }^{27}$ 와 일치하는 것이다.

두 번째로 정서 및 행동평가에 있어 청소년 스스로가 보고 한 것과 보호자가 보고한 것이 서로 차이가 있는지를 알아보 았다. 연구에 참여한 모든 청소년을 대상으로 했을 때, 내재 화 문제척도 점수를 제외한 모든 척도 점수에서 유의한 차이 가 있었다. 사회 능력 관련 척도에서는 청소년 스스로가 그들 의 양육자보다 사회성과 학업 능력이 떨어진다고 보고하였 다. 그러나 행동문제 관련 하위척도에서는 청소년 스스로가 보고한 점수가 그 양육자가 보고한 점수보다 더 높았다. 이와 같은 결과는 본 연구에 참여한 청소년이 그 보호자가 생각하 는 것보다 자신의 사회적 능력이 더 부족하다고 생각하며 정 서와 행동적인 측면에서의 적응력도 더 낮다고 보고하였음 을 나타낸다. 그러나 비행청소년 집단과 일반청소년 각각의 차이 검증에서 유의한 집단 간 차이가 있음이 확인되었는데, 일반청소년이 비행청소년보다 $\mathrm{K}-\mathrm{YSR}$ 과 $\mathrm{K}-\mathrm{CBCL}$ 점수 차가 유의한 수준으로 더 큰 것으로 확인되었다. 사회능력척도에 서도 비행청소년에 비해 일반청소년들은 그들의 보호자가 보 고한 것보다 자신의 사회성과 학업 능력이 더 떨어진다고 보 고하였으며 위축, 신체화 문제, 우울/불안, 사회적 미성숙 등 의 문제행동 관련 척도 점수도 유의한 수준으로 더 높았다. 앞서 외상경험은 비행청소년이 일반청소년보다 더 많은 것으 로 나타났는데, 정서 및 행동문제에 관한 부모-자녀의 보고
는 비행청소년보다 일반청소년이 더 큰 차이를 보였다. 이러한 결과는 본 연구에 참여한 비행청소년이 소년원에 수감된 청소 년들로 부적응 문제가 뚜렷하여 부모가 자녀의 문제행동을 분명하게 인지하고 있어 부모-자녀 간 점수 차이가 일반청소 년보다 크지 않았을 가능성이 있다. 그러나 일반청소년의 경우, 보호자는 자녀의 문제행동을 더 양호한 것으로 평가하였으나, 당사자인 청소년은 그 보호자가 관찰한 것보다 문제행동이 더 심하다고 보고하여 일반청소년 집단의 경우, 청소년 적응에 관해 부모-자녀 지각의 차이를 줄여 줄 수 있도록 돕는 부모 교육이 필요할 수 있음을 시사하는 것으로 보인다.

세 번째로 청소년 스스로 평가한 적응력과 보호자가 평가한 청소년 적응력과의 상관관계를 살펴본 결과, 비행청소년은 사 회능력 측면에서는 청소년 자신과 보호자가 보고한 것에서 유 의미한 상관을 보이지 않았다. 행동문제 측면에서는 내재화 척도 점수와 상관이 있었지만, 내재화 문제에 속하는 우울/불 안, 위축 등의 세부 하위 영역은 상관이 없었다. 그러나 사회적 미성숙과 비행, 그리고 외현화척도에서는 유의미한 상관을 보 여 청소년 자신이나 보호자가 비행청소년에 대해 사회적으로 미숙하며 문제행동을 많이 행하는 데에는 미미하나마 어느 정 도의 의견 일치가 있었다.

비행청소년과는 달리 일반청소년은 사회능력뿐 아니라 행 동문제의 모든 영역에서 청소년과 보호자의 보고가 유의미한 상관이 있는 것으로 나타났다. 특히 사회능력척도 중에서 학 교적응과 관련된 청소년의 자가 보고와 보호자의 보고가 가 장 높은 상관을 보였고 그 다음으로 행동문제척도 중에서 주 의력 문제 영역에서의 상관이 높았다. 그리고 우울과 불안뿐 아니라 전반적인 내재화척도 점수도 유의미한 상관을 보였다. 이러한 결과는 일반청소년의 경우 청소년 스스로나 보호자 모 두 학교 적응력이나 학업에 더 많은 주의를 기울이고 있는 것 이 반영된 것일 수 있다.

본 연구에서 청소년의 $\mathrm{K}-\mathrm{YSR}$ 과 보호자의 $\mathrm{K}-\mathrm{CBCL}$ 의 전반 적인 점수 상관은 비행 청소년이 0.192였던 반면, 일반 청소년 은 0.296에 해당했는데 이는 청소년과 부모 간 평가 일치도가 평균 . 25 였다는 것 28 과 $\mathrm{K}-\mathrm{YSR}$ 과 $\mathrm{K}-\mathrm{CBCL}$ 의 상관이 .11-.34 로 나타난 국내에서 수행된 연구 결과와도 유사한 것이다.29) 비록 그 정도는 미미할지라도 본 연구가 청소년의 적응에 대 한 청소년 자신과 그 보호자의 보고 간 관계를 살펴본 것이라 는 점에서 볼 때, 일반청소년에게서 모든 적응능력척도가 서로 상관이 있는 것으로 나타난 본 연구 결과는 비행청소년보다 일반청소년의 보호자가 청소년에게 좀 더 많은 주의를 기울 이고 있다는 것을 반영한 것으로 해석해 볼 수도 있다.

네 번째로, 청소년의 아동기외상경험과 청소년 적응 지표 간 관계를 알아보았다. 먼저 청소년이 보고한 아동기외상경 
험과 K-YSR과의 관계를 살펴본 결과, 비행청소년의 경우 아 동기외상경험은 사회적 능력과 가장 높은 상관(-.335)을 보여 아동기외상경험이 많을수록 사회능력이 더 떨어짐을 보여 주 었다. 또한 아동기외상경험은 위축, 우울/불안, 비행행동, 공 격행동과 작지만 유의한 상관을 보였으나 전반적인 내재화, 외현화 점수와는 유의미한 상관을 보이지는 않았다. 비록 우 울/불안과도 유의한 상관을 보이기는 하였지만 비행청소년의 아동기외상경험은 사회 적응력의 저하와 외현화 문제와 더 관 련이 있는 것으로 보인다. 비행행동은 여러 가지 심리적 부적 응과 관련이 있을 수 있는데, 본 연구 결과를 토대로 살펴보 면 외상경험이 있는 비행청소년일 경우, 그렇지 않은 청소년보 다 사회적응능력이 더 떨어져 비행행동에 연루될 가능성이 있다고 볼 수 있어 비행청소년 중에서도 외상경험이 있는 청소 년들을 선별하여 사회적응력 향상을 도와주어야 할 것으로 생각된다.

일반청소년의 경우에 있어서는 비행청소년과는 달리 아동 기외상경험과 사회능력은 서로 관련이 없는 것으로 나타났으 나 행동문제 영역에서는 아동기외상보고 점수와 모든 하위 척도 점수가 유의미한 정적 상관을 보여 아동기외상경험이 많 을수록 부적응을 경험할 수 있음을 시사하였다. 그 중에서 도 아동기외상경험은 내재화척도와 가장 높은 상관을 보였으 며 그 다음으로 행동문제 영역 중 주의력 문제와 유의미한 정적 상관을 보여 비행청소년들처럼 뚜렷한 문제행동을 보이 지 않는다하더라도 일반청소년들의 아동기외상경험을 탐색 한 후 이들의 심리적 부적응에 대한 치료적 개입이 필요함을 시사한다.

마지막으로 청소년의 아동기외상경험의 보고와 보호자가 평 가한 청소년 적응력과의 관계를 살펴본 결과, 비행청소년의 경우 $\mathrm{K}-\mathrm{CBCL}$ 의 모든 지표 점수와 유의미한 상관이 없는 것 으로 확인되었다. 그러나 일반청소년의 경우, 청소년 자녀의 아동기외상경험은 사회능력과 부적인 상관이 있었으며, 위축, 불안/우울, 사회적 미성숙, 주의력 문제, 비행행동, 공격행동, 그 리고 내재화와 외현화와 정적인 상관을 보였다. 비록 상관의 정도가 작기는 하였지만 자녀의 아동기외상경험은 일반청소 년의 부모가 인식하는 자녀의 부적응과도 관련이 있음을 시 사하는 결과라 할 수 있다. 비행청소년의 결과는 그들의 부 모-자녀관계를 반영하는 것으로 비행청소년의 부모는 일반 청소년의 부모보다 자녀의 부적응을 민감하게 인식하지 못하 고 있음을 반영하는 것일 수 있다.

그동안 청소년의 아동기외상경험과 적응 간 관계 연구는 주 로 청소년 스스로가 보고한 자료를 중심으로 진행되어 왔었 다. 비록 아동보다는 청소년이 자신의 내적인 상태나 경험에 대해 잘 보고할 수는 있지만 그래도 아직 성인보다는 그러한
능력이 잘 발달되어 있지는 못한 상태이다. 따라서 청소년의 적응 능력을 살펴볼 때에는 다양한 정보원으로부터 얻은 자 료들을 함께 고려해 보는 것이 도움이 될 것이다. 특히 소년 원에 입소된 비행청소년들을 대상으로 청소년 문제행동에 관 한 부모의 평정치와 청소년 자신의 평정치와의 관계를 살펴 본 연구는 거의 없기 때문에 본 연구 결과는 의의가 있다. 그 러나 본 연구는 몇 가지 제한점을 가진다. 무엇보다도 비행청 소년의 $\mathrm{CTQ}$ 와 $\mathrm{K}-\mathrm{CBCL}$ 상관관계에 관한 본 연구 결과를 해석시 주의가 필요하다. 왜냐하면 비행청소년 집단과 일반 청소년 집단이 $\mathrm{CTQ}$ 와 $\mathrm{K}-\mathrm{CBCL}$ 에서 서로 차이를 보인 것은 $\mathrm{K}-\mathrm{CBCL}$ 보고자가 누구였는지와도 관련이 있을 수 있기 때 문이다. 일반청소년의 경우 $\mathrm{K}-\mathrm{CBCL}$ 은 모두 부모가 완성한 것으로 그 중에서도 어머니가 완성한 것이 $88.5 \%$ 에 이르렀 다. 반면, 비행청소년은 부모가 완성한 것이 $90.3 \%$ 였지만 그 중에서 아버지가 완성한 것이 $47.2 \%$, 어머니가 작성한 것이 43.1\%가 그리고 나머지 9.7\%는 조부모님, 나이 차이가 나는 형제들로 다양했다. 평가자의 다양성이 본 연구 결과에도 영 향을 주었을 가능성이 있으므로 향후 연구에서는 일치된 평 가자를 통해 비교해 보아야 한다. 둘째, 소년원에서 보호자에 게 자녀의 행동문제에 관한 정보를 얻는 데에 어려움이 많아 더 많은 비행청소년들을 대상으로 하지 못하였다는 점에서 본 연구 결과는 조심스럽게 해석이 되어야 할 것으로 생각된 다. 셋째, 비행청소년과 일반청소년 모두에게 연구 동의서를 얻은 후 실시하였다고는 하지만 비행청소년에 비해 일반청소 년의 연구 참여 의사가 더 높았는데 일반청소년의 경우 연구 에 동의한 학생과 부모가 갖는 선택 편향이 연구 결과에 영향 을 미쳤을 가능성도 배제할 수 없다. 넷째, 아동기에 경험한 외 상이 그 이후에 경험한 외상보다 영향력이 클 수는 있지만 아 동기외상경험이 어느 시점에서 발생했는지 또한 그 영향력이 달라질 수 있다. 그리고 본 연구에서는 비행청소년의 사례수가 너무 적어 아동기외상경험의 종류를 나누어 살펴보지 않았는 데 신체학대, 정서학대, 성학대, 정서방임, 신체방임이라는 외 상경험의 종류에 따라 적응력도 달라질 수 있음도 고려해야 한다. 마지막으로 본 연구에서는 질문지를 사용하여 아동기 학대 관련 경험을 회상하게 한 후 청소년 스스로에게 보고하 도록 하였다. 비행청소년의 경우, 부모-자녀 관계가 좋지 않아 실제보다 더 과장되게 보고하였을 가능성도 배제할 수 없다.

\section{결 론}

비행청소년들은 일반청소년에 비해 아동기외상경험이 더 많 았다. 그러나 비행청소년보다 일반청소년이 아동기외상경험 (CTQ)과 다양한 적응지표(K-YSR)와 유의미한 상관을 보였 
으며 아동기외상경험과 보호자의 보고에 의한 청소년 적응지 표 $(\mathrm{K}-\mathrm{CBCL})$ 의 상관분석에서도 동일한 결과가 확인되어 비 록 외현적으로 부적응 행동이 뚜렷하지 않다 하더라도 일반 청소년들의 적응을 돕기 위한 개입에 있어 아동기외상경험의 탐색이 필요하다.

중심 단어:청소년 - 아동기외상경험 - 한국판 아동 청소년 행 동평가척도·한국판 청소년 자기행동평가척도.

\section{References}

1) Munson CE. Overview of diagnosis and treatment of psychological trauma in children. Early Child Dev Care 1995;106:149-166.

2) Chang YJ. Psychological trauma and therapeutic intervention in childhood. J Soc Sci Res Institute SWU 2010;17:175-197.

3) Cole PM, Putnam FW. Effect of incest on self and social functioning: a developmental psychopathology perspective. J Consult Clin Psychol 1992;60:174-184.

4) Shaw JA. Children, adolescents and trauma. Psychiatr Q 2000;71: 227-243.

5) Allen JG. Coping with Trauma: A Guide to Self-Understanding. Washington, DC: American Psychiatric Press;1995.

6) Gold SR, Milan LD, Mayall A, Johnson AE. A cross-validation study of the Trauma Symptom Checklist: the role of mediating variables. J Interpers Violence 1994;9:12-26.

7) Hovens JG, Wiersma JE, Giltay EJ, van Oppen $P$, Spinhoven $P$, Penninx BW, et al. Childhood life events and childhood trauma in adult patients with depressive, anxiety and comorbid disorders vs. controls. Acta Psychiatr Scand 2010;122:66-74.

8) Bremner JD, Southwick SM, Johnson DR, Yehuda R, Charney DS. Childhood physical abuse and combat-related posttraumatic stress disorder in Vietnam veterans. Am J Psychiatry 1993;150:235-239.

9) Shields A, Cicchetti D. Parental maltreatment and emotion dysregulation as risk factors for bullying and victimization in middle childhood. J Clin Child Psychol 2001;30:349-363.

10) Allen B, Lauterbach D. Personality characteristics of adult survivors of childhood trauma. J Trauma Stress 2007;20:587-595.

11) Famularo R, Kinscherff R, Fenton T. Psychiatric diagnoses of maltreated children: preliminary findings. J Am Acad Child Adolesc Psychiatry 1992;31:863-867.

12) Courtois CA. Complex trauma, Complex reactions: assessment and treatment. Psychol Trauma: Theory, Practice, Policy 2008;S:86-100.

13) Kim J, Cicchetti D, Rogosch FA, Manly JT. Child maltreatment and trajectories of personality and behavioral functioning: implications for the development of personality disorder. Dev Psychopathol
2009;21:889-912.

14) Hoffman-Plotkin D, Twentyman CT. A multimodal assessment of behavioral and cognitive deficits in abused and neglected preschoolers. Child Dev 1984;55:794-802.

15) Cerezo MA. Parent-Child Conflict, Coercive Family Interaction and Physical Child Abuse. In: Klein CA, editor. Multidisciplinary Perspectives on Family Violence. New York: Routledge;1997.

16) Kim JH, Noh SH. An empirical study on the relationship between social classes and juvenile delinquency. Korean J Criminol 1989;4: 197-237.

17) Jo YJ, Suk JY, Park IJ. The effects of child abuse on children from their parents on self-control and aggressive behavior of adolescents: differences between ordinary and delinquent adolescents. Stud Korean Youth 2005;16:133-164.

18) Achenbach TM. Manual for Child Behavior Checklist 4-18, 1991 Profile. Burlington: University of Vermont Department of Psychiatry;1991.

19) Kang HJ, KooK SH. Patterns related to parent and adolescent reports of problem behavior in adolescents with internalization and externalization disorders. Korean J Clin Psychol 2010;29:907-925.

20) Krol NP, De Bruyn EE, Coolen JC, van Aarle EJ. From CBCL to DSM: a comparison of two methods to screen for DSM-IV diagnoses using CBCL data. J Clin Child Adolesc Psychol 2006;35:127-135.

21) Achenbach TM. Manual for the Youth Self-Report and 1991 Profile. Burlington, University of Vermont Department of Psychiatry;1991.

22) Oh KJ, Bae DH. A study on two subtyes of aggression based on the K-CBxCL aggressive behavior subscale. Korean J School Psych 2010; 7:371-390.

23) Ha EH, Lee SJ, Oh KJ, Hong KE. Parent-adolescent agreement in the assessment of behavior problems of adolescents: comparison of factor structures of K-CBCL and YSR. Korean J Child Adolesc Psychiatry. 1998;9:3-12.

24) Bernstein DP, Fink L. Childhood Trauma Questionnaire: A retrospective self-report manual. San Antorio, TX: Harcourt Brace;1998.

25) Oh KJ, Ha EH, Lee HL, Hong KE. Korean Youth Self Report. Seoul; Jung-Ang Aptitude Publication;2001.

26) Oh KJ, Lee HL, Hong KE. Korean Child Behavior Checklist. Seoul; Jung-Ang Aptitude Publication;1997.

27) Stewart A, Livingston M, Dennison S. Transitions and turning points: examining the links between child maltreatment and juvenile offending. Child Abuse Negl 2008;32:51-66.

28) Achenbach TM, McConaughy SH, Howell CT. Child/adolescent behavioral and emotional problems: implications of cross-informant correlations for situational specificity. Psychol Bull 1987;101:213232.

29) Ko EJ, Ha EH. The cross-informant agreement on behavior problems between mother and adolescent reports: according to maternal and adolescent depression. Korean J Clin Psychol 2008;27:103-116. 